[Original]

\title{
The Relationship Between Fear-avoidance Beliefs in Employees with Chronic Musculoskeletal Pain and Work Productivity: A Longitudinal Study
}

\author{
Ryosuke Sugano ${ }^{1 *}$, Kazunori Ikegami ${ }^{1}$, Hajime Ando ${ }^{1}$, Hiroki Nozawa ${ }^{1}$, Satoshi Michir ${ }^{1}$, Miho Kondo ${ }^{2}$, \\ Hitomi Iмото $^{3}$, Azusa Shima ${ }^{4}$, Yuichiro Kawatsu ${ }^{4}$, Yoshihisa Fujino ${ }^{5}$ and Akira Ogami ${ }^{1}$ \\ ${ }^{1}$ Department of Work Systems and Health, Institute of Industrial Ecological Sciences, University of Occupational and \\ Environmental Health, Japan. Yahatanishi-ku, Kitakyushu 807-8555, Japan \\ ${ }^{2}$ Stanley Electric Co., Ltd. Hatano Factory, Hadano 257-8555, Japan \\ ${ }^{3}$ Kyushu Labour Bank, Chuou-ku, Fukuoka 810-0074, Japan \\ ${ }^{4}$ Occupational Health Care Office, Heiwado Co., Ltd. Hikone 522-0054, Japan \\ ${ }_{5}^{5}$ Department of Environmental Epidemiology, Institute of Industrial Ecological Sciences, University of Occupational \\ and Environmental Health, Japan. Yahatanishi-ku Kitakyushu 807-8555, Japan
}

\begin{abstract}
This study aimed to identify risk factors for chronic musculoskeletal pain (CMSP) and sought to examine the effect of fear-avoidance beliefs (FABs) on work productivity in workers with CMSP. We performed a longitudinal study using self-administered questionnaires given to employees in three different industries between April 2016 and March 2017. The questionnaire concerned background characteristics, work-related factors and musculoskeletal pain, the Work Functioning Impairment Scale (WFun), and the Japanese version of the Tampa Scale for Kinesiophobia (TSK-J). We performed logistic regression analysis to evaluate factors affecting CMSP and a multi-way analysis of variance to analyze the relationship between FABs and CMSP and the effect of FABs on the ability to function at work. Age (odds ratio $[\mathrm{OR}]=1.02,95 \%$ confidence interval $[\mathrm{CI}]: 1.00-1.03$ ), mean working hours (OR $=1.18,95 \%$ CI: $1.04-1.33)$, and changes in working hours ( $\mathrm{OR}=1.18,95 \% \mathrm{CI}: 1.02-1.37)$ were significantly associated with CMSP. Regarding FABs, we found that the stronger the FAB, the greater the WFun score, and that an increase in FABs resulted in a significant increase in WFun scores. This study demonstrated that long or increased working hours may be risk factors for CMSP, and that stronger FABs in those with CMSP are associated with decreased ability to function at work. In addition, measures to reduce FABs in workers with CMSP may be effective.
\end{abstract}

Keywords : fear-avoidance beliefs, chronic musculoskeletal pain, work productivity, presenteeism, occupational health.

(Received October 7, 2019, accepted December 26, 2019)

\section{Introduction}

Approximately $10 \%$ to $20 \%$ of Japanese people suffer from chronic pain, and it has been reported that the prevalence of musculoskeletal pain, especially in the lower back, neck, and shoulder regions, is very high [1-4].
Studies focusing solely on musculoskeletal pain among those with chronic pain have also been conducted, by Nakamura et al suggesting great interest in this topic [5]. In a previous study, we conducted a cross-sectional survey on the same subjects as this study and found that $34 \%$ had chronic musculoskeletal pain [6]. In Eu-

*Corresponding Author: Ryosuke Sugano, Department of Work Systems and Health, Institute of Industrial Ecological Sciences, University of Occupational and Environmental Health, Japan. 1-1 Iseigaoka Yahatanishi-ku Kitakyushu 807-8555, Japan, Tel: +81-93-691-7470, Fax: +81-93-601-2667, E-mail: ryosuke-sugano@med.uoeh-u.ac.jp 
rope, it has been reported that $>20 \%$ of employees have musculoskeletal pain, and interventions to prevent work-related musculoskeletal pain have been investigated [7]. While it is necessary to identify the precise nature of CMSP in workers and to examine effective countermeasures, few studies regarding CMSP among Japanese workers have been undertaken.

Chronic pain has been shown to result in decreased productivity in workers [8]. The relationship between decreased work productivity and CMSP located in the lower back, neck, shoulder, and upper arm regions has been previously investigated [9-11]. Productivity loss may be due to absenteeism (absence from work or sick leave due to health problems) or presenteeism (attending work despite health problems). In one study undertaken in the United States, economic losses and health expenditures due to presenteeism were estimated to be approximately four times higher than those due to absenteeism [12]. Moreover, it has been suggested that many workers with lower back pain continue working despite pain [13]. Therefore, more information is needed concerning the relationship between CMSP and productivity loss resulting from decreased ability to function at work due to presenteeism.

Risk factors for overall CMSP, including obesity, drinking, smoking, insomnia and heavy physical activity, have been investigated [14-17]. In our previous study conducted with the same subjects as this study, we indicated that lack of sleep and overtime work are associated with chronic musculoskeletal pain [18]. In addition, site-specific CMSP risk factors, work history, physical activity, and psychological stress were investigated with respect to chronic lower back pain [19], while self-rated health condition and somatization have been examined with respect to chronic arm and knee pain [20,21]. Among the psychological factors, we focused on fear-avoidance beliefs (FABs) as a risk factor of chronic lower back pain. FABs arise when there is a pessimistic or catastrophic interpretation of pain while it is being experienced that causes fear of or anxiety about re-occurring pain such that the person avoids behaviors that may cause that pain. FABs cause muscle weakness and a decreased range of motion through over-suppressing activities that may trigger pain all in order to avoid pain recurrence. In addition, excessive attention to painful stimuli has been reported to cause depression and lower the pain perception threshold, leading to chronic pain. Due to a decrease in the ability to pay attention to other activities, the ability to perform cognitive tasks is reduced $[22,23]$. We hypothesized that avoiding painful movements would have a negative impact on the ability to function at work, such that the more intense the $\mathrm{FAB}$, the greater the reduced ability to function at work. Furthermore, we presumed that FABs also result in CMSP in regions other than the lower back, and that the more intense the FABs, the greater the reduced ability to function at work due to CMSP in those regions. Few studies have investigated the relationship between FABs and ability to function at work and, to our knowledge, this is the first longitudinal study aimed to identify risk factors for CMSP to analyze the relationship between FABs and loss of productivity.

\section{Subjects and Methods}

\section{Study design and setting}

In this longitudinal study, we used a self-administered questionnaire for workers at 118 worksites in the manufacturing, financial, and retail industries. We followed participants from April 2016 to March 2017, administering a baseline questionnaire in June 2016 and a follow-up questionnaire available from December 2016 to January 2017. The questionnaires included questions about the workers and their work-related attributes, musculoskeletal pain, the Work Functioning Impairment Scale (WFun), and the Japanese version of the Tampa Scale for Kinesiophobia (TSK-J).

\section{Participants}

In the baseline survey, we distributed a questionnaire that included an overview of the study and an informed consent form to 3,406 workplace employees, and responses were obtained from those who had consented to participate in the study. In the follow-up survey, the questionnaire was re-distributed to the same employees who had responded to the baseline questionnaire and no recommendation was made for employees who hadn't answered the questions. The subjects were selected from workplaces at which the first author or coauthors worked as an occupational physician. The data were collected both electronically and on paper. 


\section{Measurements}

Baseline characteristics and work-related factors

Baseline characteristics included age, sex, education level, and illnesses requiring treatment. Work-related factors such as business type, job content, job position, frequency of midnight work, and working hours at the office were surveyed using a self-administered questionnaire. Industries were categorized according to the Japanese Standard Industry Classification as determined by the Ministry of Internal Affairs and Communications of Japan. Workers were asked to categorize their jobs according to a self-administered format. The three categories comprised physical labor (workers mainly engaged in moving/working at production sites, e.g., driving and maintenance), intellectual labor (mainly using their expertise working in general offices, e.g., using personal computers or in computeraided design), and emotional labor (work mainly communicating with people, e.g., sales and marketing, bank teller or working with personnel in stores). We defined midnight work as working from $10 \mathrm{PM}$ to $5 \mathrm{AM}$ and asked participants to report the number of midnight work hours per month. Employees were asked to selfreport the number of hours worked per day within the past three months. Overtime work per month was calculated as follows: 20 (the average number of working days per month in Japan) $\times$ the number of working hours per day reported by the workers minus 8 hours (the statutory working hours per day in Japan).

\section{Measurements of musculoskeletal pain}

Workers were asked questions about all musculoskeletal pain sites and those sites most affecting their work using a total of eight available response options. Seven human body charts indicating pain at seven different sites (neck, shoulders, upper limb, back, lower back, hip joint, knee) were used for collecting responses. An 'other pain' location option was available for workers to indicate other more specific pain sites (Appendix 1). In terms of duration of pain, the workers were asked to respond as follows: (1) $\leq 1$ month, (2) 1-3 months, or (3) $>3$ months. Pain frequency was also determined as follows: (1) almost daily, (2) 2-5 days/week, (3) approximately 1 day/week, or (4) approximately $1-2$ times/month.

\section{Definition of chronic musculoskeletal pain}

The International Association for the Study of Pain (IASP) defines chronic pain as follows: "Chronic pain has been recognized as that pain which persists past the normal time of healing and with nonmalignant pain, three months is the most convenient point of division between acute and chronic pain" [24]. Therefore, in this study, we defined CMSP as the presence of musculoskeletal pain lasting more than three months.

\section{Group categorization according to musculoskeletal pain status}

Workers were categorized into four CMSP groups: those who reported no CMSP in both baseline and follow-up surveys were classified as "No prevalence of CMSP;" those who reported no CMSP in the baseline survey and then reported CMSP in the follow-up survey were classified as "Developing CMSP;" those who reported CMSP in the baseline survey but reported no CMSP in the follow-up survey were classified as "Recovering from CMSP;" and workers who reported CMSP in both surveys were classified into the "Persistent CMSP" group.

\section{Work Functioning Impairment Scale (WFun)}

The WFun questionnaire comprised seven items concerning the correlation between current working conditions and well-being. Workers were asked to respond using a five-point Likert scale as follows: (1) almost daily, (2) $\geq 2$ days/week, (3) $\geq 1$ days/week, (4) $\geq 1$ days/month, or (5) none, in order to measure the degree of non-disease-specific work-related disability $[25,26]$. The scores ranged from 7 to 35 and the higher the score, the greater the decreased ability to function at work.

\section{Japanese version of the Tampa Scale for Kinesiophobia (TSK-J)}

This questionnaire comprised 17 items concerning beliefs and perceptions about pain and measured the intensity of FABs using a four-point Likert scale for responses as follows: (1) strongly disagree, (2) disagree, (3) agree, or (4) strongly agree [27-29]. The scores ranged from 17 to 68 and the higher the score, the stronger the FAB. While FABs have been frequently observed in people with musculoskeletal pain, 
only workers with musculoskeletal pain were evaluated for TSK-J scores in this study.

Group categorization according to degree of FAB in employees with musculoskeletal pain

In order to assess the relationship between FABs associated with musculoskeletal pain and the ability to function at work, we grouped workers with musculoskeletal pain according to their degree of FAB. Workers with musculoskeletal pain (transient and chronic) were divided into four groups according to quartiles of TSK-J scores for cross-sectional assessment in the baseline survey: TSK-J $\leq 36$, TSK-J 37-39, TSK-J $40-43$, and TSK-J $\geq 44$. For the longitudinal analysis of baseline and follow-up surveys, the first and third quartiles of the change in TSK-J score (baseline TSKJ score - follow-up score) were used to create three groups: $\Delta$ TSK-J $<-2$ (improvement group), $\Delta$ TSK-J -2 to 2 (no change group), and $\triangle T S K-J>2$ (deterioration group).

\section{Statistical analysis}

We first compared individual and occupational factors across the four categories of CMSP status using a chi-squared test or a one-way analysis of variance (ANOVA). Subsequently, we conducted a logistic regression analysis with a forced-injection method using data from workers in the No Prevalence of CMSP and Developing CMSP groups to evaluate factors affecting the chronicity of musculoskeletal pain. Response variables included the presence or absence of CMSP, and explanatory variables included sex, age, body mass index (BMI), and employees' other personal and occupational factors including illnesses requiring treatment, night shift work, mean working hours, mean sleeping time and changes in working hours. Age, BMI, mean working hours, mean sleeping time and changes in working hours were continuous variables. To avoid multicollinearity, the variance inflation factor (VIF) was calculated for each explanatory variable, confirming that VIF was $<2$ for all variables.

To assess the relationship between CMSP and the ability to function at work, we performed repeated measures ANOVA with response variables such as the WFun score, explanatory variables such as CMSP classification and the time of the survey, and potential confounders such as age and sex.

Finally, we analyzed the relationship between FABs associated with musculoskeletal pain and the ability to function at work. The cross-sectional analysis involved the four groups created according to the baseline TSK-J score quartile. The multivariate ANOVA involved response variables such as the WFun score, explanatory variables such as TSK-J score, and potential confounders such as age, sex and existence of musculoskeletal pain as reported in the follow-up survey. A longitudinal analysis was performed using a multidimensional repeated measures ANOVA with response variables such as the WFun score, explanatory variables such as changes in the TSK-J score and the time of the survey, and potential confounders such as age and sex. Subsequent multiple comparison tests were performed using the Bonferroni method. The significance level was set at $P<0.05$. All statistical analyses were performed using SPSS 24.0J (IBM SPSS Japan, Inc., Tokyo, Japan).

\section{Ethical approval}

This study was conducted in accordance with the Declaration of Helsinki and was approved by the Medical Research Ethics Committee at the University of Occupational and Environmental Health, Japan (No. H28-001). The outline of the research was explained to the persons in charge at each worksite and to the occupational health staff, and consent was obtained. In addition, informed consent was obtained from all employees participating in the study.

\section{Results}

\section{Participants}

A total of 2,154 workers agreed to participate in the study and subsequently responded to the questionnaire. Of these, 99 were excluded from the analysis because of incomplete responses, resulting in a sample size of 2,055 participants included in the analysis. Of 2,055 workers who completed the questionnaire in the baseline survey, 1,673 also responded to the questionnaire in the follow-up survey. The second survey included 1,488 workers for a follow-up rate of $72.4 \%$. We excluded 91 workers who did not answer questions required for analysis such as sex, age, presence of illness requiring treatment, and/or working hours; 70 workers 


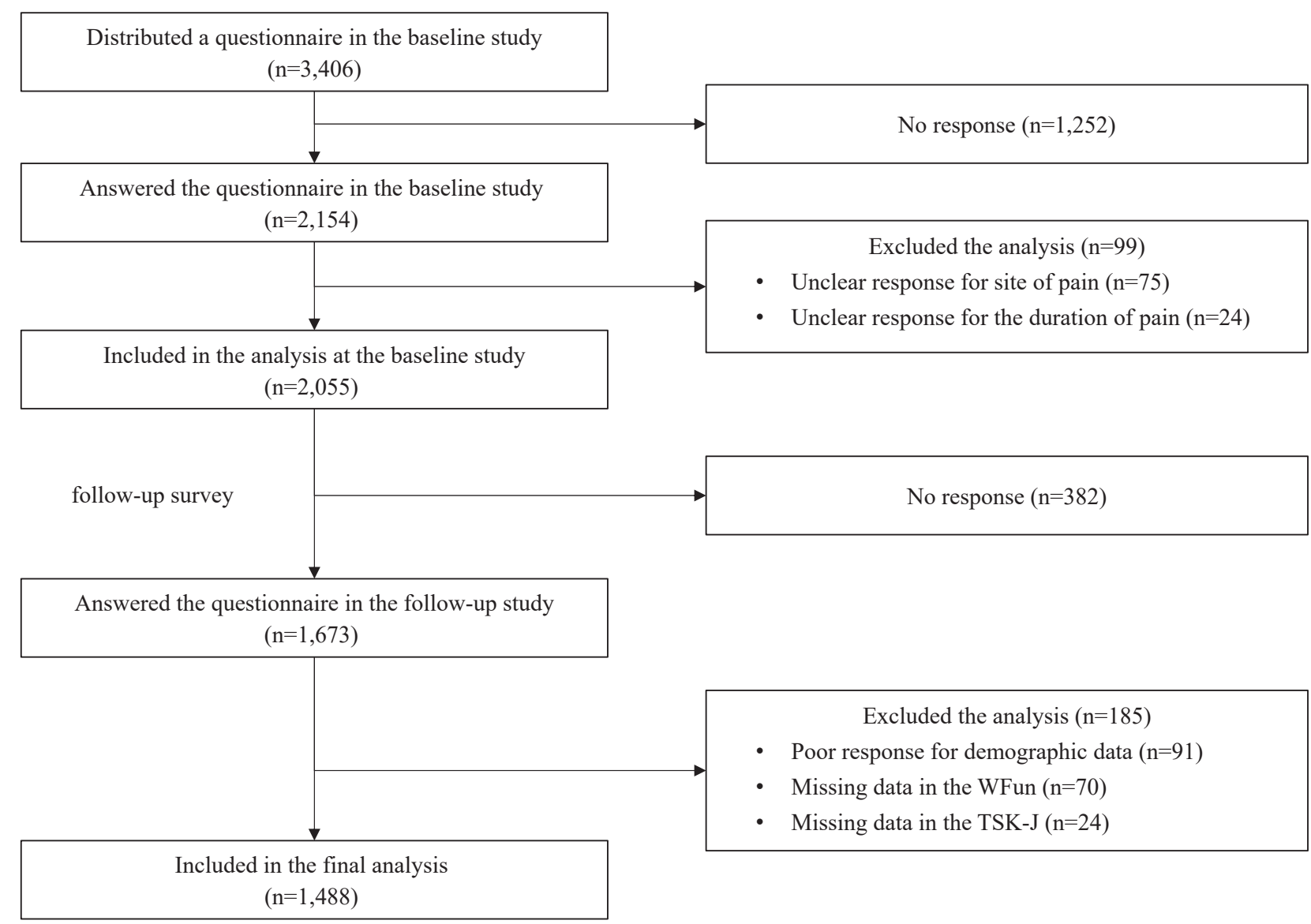

Fig. 1. Flowchart of study participants.

with missing data for WFun; and 24 workers with missing data for TSK-J (Fig. 1). The mean age (standard deviation) of all participants was 41.2 (12.2) years, and $80.8 \%$ were men. According to the CMSP classification, there were 975 (65.5\%) workers in the No Prevalence of CMSP group, 132 (8.9\%) in the Recovering CMSP group, 169 (11.4\%) in the Developing CMSP group, and $212(14.3 \%)$ in the Persistent CMSP group (Table 1).

Comparing individual and occupational factors according to CMSP

Our findings showed that there were significant differences in personal factors between the four groups according to age $(\mathrm{F}[3,1484]=9.465, P<0.001)$, mean sleeping time $(\mathrm{F}[3,1484]=6.707, P<0.001)$ and the presence of illnesses requiring treatment $\left(\chi^{2}=27.895\right.$, $P<0.001)$. In the multiple comparison test, the mean age in the No Prevalence of CMSP group was significantly younger than that of the other three groups and mean sleep time in the No Prevalence of CMSP group was significantly longer than that of Recovery and Persistent CMSP groups. In the residual analysis of illnesses requiring treatment, the proportion of workers with illnesses requiring treatment was significantly higher in the Recovering and Persistent CMSP groups and significantly lower in the No Prevalence of CMSP group (Table 1).

Regarding occupational factors, there was a significant difference between the four groups in mean working hours $(\mathrm{F}[3,1484]=5.937, P=0.001)$. According to the multiple comparison test, mean working hours were significantly shorter in the No Prevalence of CMSP group than in the Recovering CMSP group (Table 1). 
Table 1. Demographics and work-related factors of the workers

\begin{tabular}{|c|c|c|c|c|c|c|c|c|}
\hline & & $\begin{array}{l}\text { All } \\
\text { participants } \\
(\mathrm{n}=1,488) \\
\%\end{array}$ & $\begin{array}{l}\text { No prevalence } \\
\text { of CMSP } \\
(\mathrm{n}=975) \\
\%\end{array}$ & $\begin{array}{l}\text { Recovering } \\
\text { CMSP } \\
(\mathrm{n}=132) \\
\%\end{array}$ & $\begin{array}{l}\text { Developing } \\
\text { CMSP } \\
(\mathrm{n}=169) \\
\%\end{array}$ & $\begin{array}{l}\text { Persistent } \\
\text { CMSP } \\
(\mathrm{n}=212) \\
\%\end{array}$ & Statistics & $P$ \\
\hline \multicolumn{9}{|l|}{ Personal factors } \\
\hline \multicolumn{2}{|l|}{ Age (yr) } & $41.2(12.2)^{\dagger}$ & $40.0(12.3)^{\dagger}$ & $43.3(11.6)^{\dagger}$ & $43.1(11.7)^{\dagger}$ & $43.9(12.2)^{\dagger}$ & $F=9.465$ & $<0.001 *$ \\
\hline \multirow[t]{2}{*}{ Sex } & Female & 19.2 & 18.3 & 22.0 & 21.3 & 20.3 & $\chi^{2}=1.852$ & 0.604 \\
\hline & Male & 80.8 & 81.7 & 78.0 & 78.7 & 79.7 & & \\
\hline \multicolumn{2}{|l|}{$\operatorname{BMI}\left(\mathrm{kg} / \mathrm{m}^{2}\right)$} & $23.0(3.6)^{\dagger}$ & $22.8(3.6)^{\dagger}$ & $23.1(3.4)^{\dagger}$ & $23.1(3.8)^{\dagger}$ & $23.3(3.5)^{\dagger}$ & $\mathrm{F}=1.191$ & 0.312 \\
\hline \multicolumn{2}{|c|}{ Mean sleeping hours (hr) } & $6.11(0.9)^{\dagger}$ & $6.2(1.0)^{\dagger}$ & $5.9(0.9)^{\dagger}$ & $6.1(0.9)^{\dagger}$ & $5.9(0.9)^{\dagger}$ & $\mathrm{F}=6.707$ & $<0.001^{*}$ \\
\hline \multicolumn{2}{|c|}{ Presence of illness requiring treatment } & 21.0 & $16.4 \nabla$ & $28.8 \boldsymbol{\Delta}$ & $28.4 \boldsymbol{A}$ & $31.1 \boldsymbol{\Delta}$ & $\chi^{2}=27.895$ & $<0.001 *$ \\
\hline \multirow[t]{3}{*}{ Smoking status } & Current smoking & 36.3 & 36.9 & 38.6 & 28.4 & 38.2 & $\chi^{2}=12.153$ & 0.059 \\
\hline & Former smoking & 25.2 & 23.5 & 23.5 & 34.9 & 26.4 & & \\
\hline & no-smoking & 38.5 & 39.6 & 37.9 & 36.7 & 35.4 & & \\
\hline \multirow[t]{5}{*}{ Education } & Junior high school & 2.8 & 3.1 & 1.5 & 3.0 & 1.9 & $\chi^{2}=10.664$ & 0.299 \\
\hline & Senior high school & 48.4 & 49.2 & 42.4 & 44.4 & 51.4 & & \\
\hline & Vocational school & 9.1 & 8.0 & 14.4 & 10.1 & 10.4 & & \\
\hline & College & 39.3 & 39.4 & 41.7 & 41.4 & 35.8 & & \\
\hline & Obscure & 0.4 & 0.3 & 0.0 & 1.2 & 0.5 & & \\
\hline \multicolumn{9}{|c|}{ Work-related factors } \\
\hline \multirow[t]{4}{*}{ Job contents } & Physical work & 48.3 & 49.4 & 44.7 & 46.2 & 46.7 & $\chi^{2}=5.069$ & 0.828 \\
\hline & Brain work & 45.1 & 44.1 & 45.5 & 46.7 & 48.1 & & \\
\hline & Emotional work & 6.6 & 6.4 & 9.8 & 7.1 & 5.2 & & \\
\hline & Obscure & 0.1 & 0.1 & 0.0 & 0.0 & 0.0 & & \\
\hline \multirow[t]{3}{*}{ Midnight work } & None & 72.4 & 71.7 & 73.5 & 72.8 & 75.0 & $\chi^{2}=6.267$ & 0.713 \\
\hline & $\leq 3$ times $/$ month & 5.6 & 5.3 & 5.3 & 6.5 & 6.1 & & \\
\hline & $\geq 4$ times/month & 22.0 & 23.0 & 21.2 & 20.7 & 18.9 & & \\
\hline \multicolumn{2}{|c|}{ Mean working hours (hr) } & $8.56(1.3)^{\dagger}$ & $8.47(1.3)^{\dagger}$ & $8.89(1.4)^{\dagger}$ & $8.74(1.4)^{\dagger}$ & $8.66(1.3)^{\dagger}$ & $\mathrm{F}=5.937$ & $0.001^{*}$ \\
\hline \multicolumn{2}{|c|}{ Changes in working hours (hr) } & $0.15(1.1)^{\dagger}$ & $0.12(1.1)^{\dagger}$ & $0.15(0.9)^{\dagger}$ & $0.37(1.3)^{\dagger}$ & $0.10(1.2)^{\dagger}$ & $\mathrm{F}=2.409$ & 0.065 \\
\hline
\end{tabular}

+ : Mean $\pm \mathrm{SD}, *: P<0.05$, Missing data were shown in Education $(\mathrm{n}=6)$ and Job content $(\mathrm{n}=1)$. CMSP: Chronic musculoskeletal pain, SD: standard deviation, BMI: Body mass index. In residual analysis after chi-square test, significantly high values were expressed as " $\mathbf{A}$ ", and significantly low values were expressed " $\nabla$ ".

\section{Assessment of factors affecting CMSP}

The factors relating to CMSP were evaluated using logistic regression analysis obtained from workers' data in the No Prevalence of CMSP and Developing CMSP groups. Three significant factors relating to CMSP were age (odds ratio (OR) $[95 \%$ confidence interval $(\mathrm{CI})]=1.02[1.00-1.03], P=0.028)$, mean working hours $(\mathrm{OR}[95 \% \mathrm{CI}]=1.18[1.04-1.33], P=$ $0.010)$, and changes in working hours $(\mathrm{OR}[95 \% \mathrm{CI}]=$ 1.18 [1.02-1.37], $P=0.027$ ) (Table 2).

Comparison of WFun scores according to CMSP classification

We compared WFun scores among the four groups according to CMSP classification. There was a sig- nificant main effect observed in the classification of $\operatorname{CMSP}(\mathrm{F}[3,1482]=6.946, P<0.001)$. In the multiple comparison test, the WFun scores in the Developing CMSP and Persistent CMSP groups were significantly higher than in the No Prevalence of CMSP group. Although there was no interaction between the classifications of CMSP and time points, the greatest increase in WFun scores among the four groups was in the Developing CMSP group (Fig. 2).

Comparison of WFun scores according to TSK-J scores in individuals with musculoskeletal pain

In the baseline survey, 694 of 1,488 workers reported having musculoskeletal pain (including all transient and chronic pain). Those with musculoskeletal pain 
Table 2. Factors associated with chronic musculoskeletal pain (CMSP)

\begin{tabular}{lcccccc}
\hline & $\mathrm{B}$ & $(\mathrm{SE})$ & Wald & Odd ratios & $95 \% \mathrm{CI}$ & $P$ \\
\hline Age & 0.02 & $(0.01)$ & 4.83 & 1.02 & $1.00-1.03$ & $0.028^{*}$ \\
Sex $^{\dagger}$ & -0.40 & $(0.23)$ & 2.88 & 0.67 & $0.43-1.06$ & 0.090 \\
BMI & 0.01 & $(0.03)$ & 0.09 & 1.01 & $0.96-1.06$ & 0.763 \\
Midnight work & 0.13 & $(0.20)$ & 0.40 & 1.14 & $0.76-1.70$ & 0.527 \\
Mean working hours & 0.16 & $(0.06)$ & 6.72 & 1.18 & $1.04-1.33$ & $0.010^{*}$ \\
Changes in working hours & 0.17 & $(0.08)$ & 4.91 & 1.18 & $1.02-1.37$ & $0.027^{*}$ \\
Mean sleeping hours & -0.08 & $(0.09)$ & 0.73 & 0.93 & $0.77-1.11$ & 0.393 \\
Presence of illness requiring treatment ${ }^{\S}$ & 0.35 & $(0.22)$ & 2.68 & 1.42 & $0.93-2.17$ & 0.102 \\
Constant & -3.40 & $(1.03)$ & 10.91 & 0.02 & $<0.001$ \\
\hline
\end{tabular}

*: $P<0.05$, Logistic regression analysis obtained from workers' data in the No Prevalence of CMSP and Developing CMSP groups. SE: standard error, CI: confidential interval, BMI: body mass index. ${ }^{\dagger}$ : Female coded 0 , male coded 1 , ${ }^{\star}$ : The participants not engaged in the midnight work coded 0 , the ones engaged coded $1, \S$ : The participants without illness requiring treatment at the baseline survey coded 0 , the ones with coded 1 .

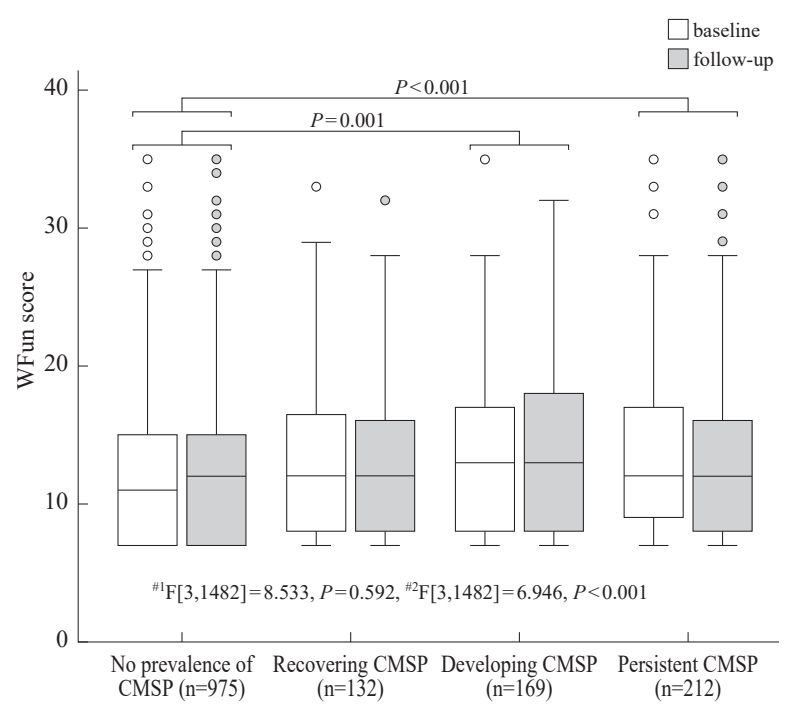

Fig. 2. Comparison of WFun scores according to the CMSP classification. A repeated measures analysis of variance (ANOVA) was conducted. Baseline: data collected in June 2016; follow-up: data collected from December 2016 to January 2017. ANOVA: analysis of variance, CMSP: chronic musculoskeletal pain, WFun: work functioning impairment scale. \#1: test of within-subjects factor (interaction between time points and classification), \#2: test of between-subjects factor (main effect of CMSP classification). The WFun score in the Developing and Persistent CMSP groups was significantly higher than in the No prevalence of CMSP group.

were divided into four groups according to the quartiles of TSK-J scores: TSK-J $\leq 36(\mathrm{n}=174)$, TSK-J 37$39(\mathrm{n}=184)$, TSK-J 40-43 $(\mathrm{n}=194)$, and TSK-J $\geq 44$ $(\mathrm{n}=142)$. WFun scores were then compared among the four groups. We observed a significant main ef-

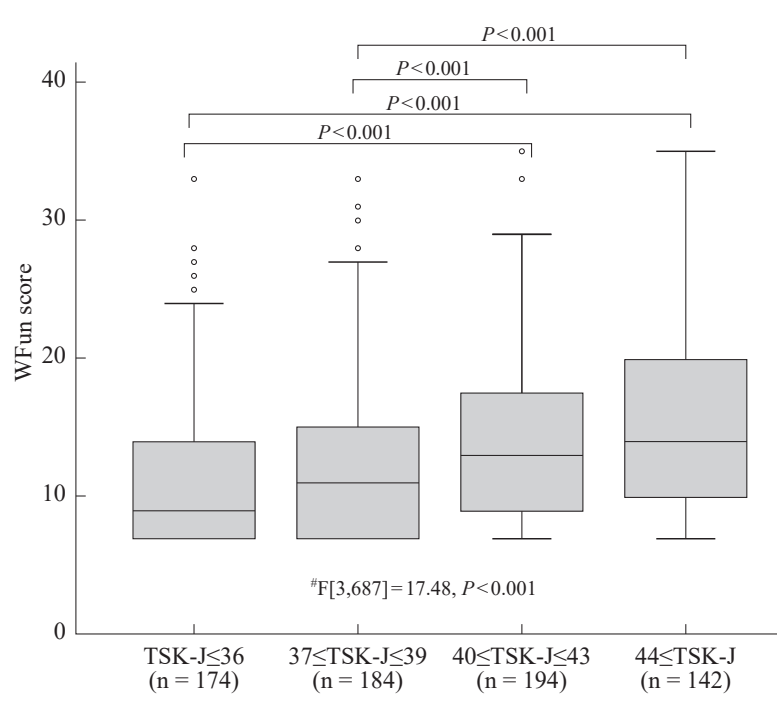

Fig. 3. Comparison of WFun scores according to TSK-J scores in individuals with musculoskeletal pain. Subjects ( $n=694)$ : workers who had musculoskeletal pain in the baseline survey. A cross-sectional analysis was conducted using the baseline survey's data. \#: the statistics of a multivariate analysis of variance (ANOVA). In the multiple comparison test, WFun scores were significantly higher in the TSK-J $\geq 44$ and the TSK-J 40-43 groups than in the TSK-J $\leq 36$ and TSK-J 37-39 groups. ANOVA: analysis of variance, WFun: work functioning impairment scale, TSK-J: the Japanese version of the Tampa Scale for Kinesiophobia.

fect $(\mathrm{F}[3,687]=17.48, P<0.001)$ in the classification according to TSK-J score. In the multiple comparison test, WFun scores were significantly higher in the TSK$\mathrm{J} \geq 44$ and the TSK-J 40-43 groups than in the TSK-J $\leq 36$ and TSK-J 37-39 groups (Fig. 3). 
Comparison of WFun scores according to categorization based on changes in TSK-J scores

At both surveys, 485 of 1,488 workers reported having musculoskeletal pain (including all transient and chronic pain). The workers were analyzed in three groups using the first and third quartiles of change in the TSK-J scores: $\Delta$ TSK-J $<-2$ (improvement group, $\mathrm{n}=133$ ), $\Delta$ TSK-J -2 to 2 (no change group, $\mathrm{n}=213$ ), and $\Delta$ TSK-J $>2$ (deterioration group, $\mathrm{n}=139$ ). While no significant main effect was found in the classification based on the change in TSK-J score, a significant interaction was found between the classification based on the change in TSK-J score and the time of the survey $(\mathrm{F}[2,480]=6.031, P=0.003)$. A simple main effect test showed that the WFun score in the follow-up survey was significantly higher than that in the baseline survey for the deterioration group (Fig. 4). Of the 3,091 participants who received the questionnaire, $1,963(63.5 \%)$ participants completed and returned

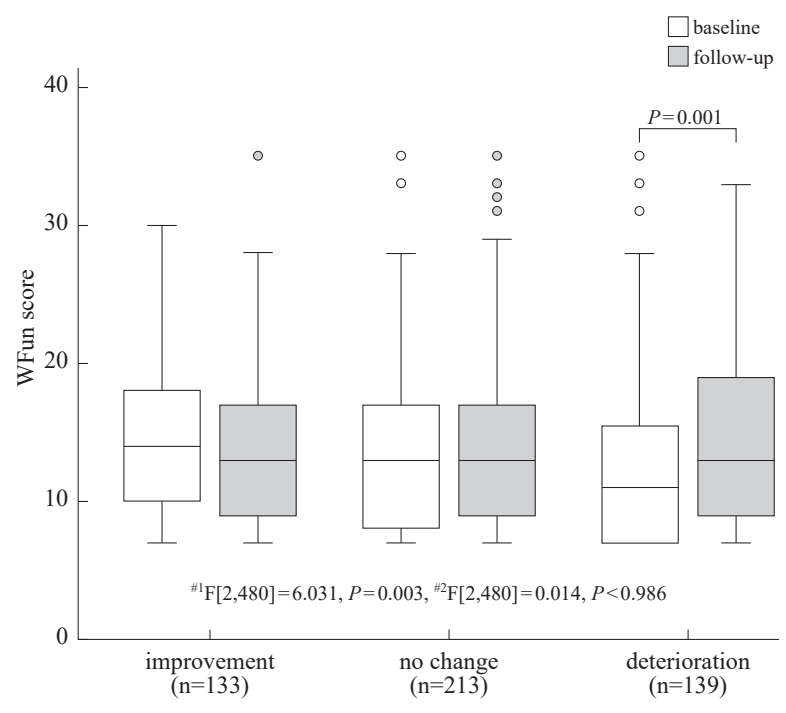

Fig. 4. Comparison of WFun scores according to categorization based on changes in TSK-J scores. Subjects $(n=485)$ : workers who had musculoskeletal pain in both baseline and follow-up surveys. A repeated measures analysis of variance (ANOVA) was conducted. Baseline: data collected in June 2016; follow-up: data collected from December 2016 to January 2017. ANOVA: analysis of variance, WFun: Work Functioning Impairment Scale, TSK-J: the Japanese version of the Tampa Scale for Kinesiophobia. $\# 1$ : test of within-subjects factor (interaction between time points and categorization), \#2: test of between-subjects factor (main effect of each categorizations). it. Because of missing values regarding sex, sleeping hours, and working hours, 206 participants were excluded from the analysis. Another 10 participants who had chronic pain that was not musculoskeletal (e.g., headache) were excluded. Finally, 1,747 participants were included in the analysis.

\section{Discussion}

The findings of this study suggest that long and increased working hours may be risk factors for CMSP in workers. Long working hours have previously been associated with anxiety, cardiovascular disease, and depression [30]. Therefore, musculoskeletal symptoms as well as cardiovascular and psychiatric symptoms should be measured and evaluated as part of the health management of workers who continuously work long hours or who work an increased number of hours. It is difficult to implement effective measures addressing CMSP in all workplaces because varying industries have differing risk factors for developing musculoskeletal pain. Currently, effective measures and intervention methods are only applied horizontally in each industry [7]. In Japan, guidelines for measures to prevent lower back pain in the workplace have been provided. Following a risk assessment of lower back pain in each industry, it has been recommended that continuous efforts be made to manage: the work environment (maintaining an appropriate workplace temperature, eliminating slippery floor surfaces, placing workbenches at an ergonomic height); the work method (automating work requiring the handling of heavy objects, avoiding taking the same posture for too long, providing appropriate breaks); and worker's health (providing health checkups for workers handling heavy objects, back pain prevention exercises). It is also recommended that occupational health education be provided for employees (e.g., education for back pain prevention). However, it is difficult to determine whether these guidelines have been well implemented, and few companies appear to have implemented appropriate preventive measures. In addition, no preventative guideline measures have been published concerning musculoskeletal pain other than lower back pain. Given that musculoskeletal pain can be improved through early workplace intervention by in- 
ternal medicine or orthopedic surgery specialists [31], occupational physicians may play a role in improving musculoskeletal pain. Furthermore, in Japan, regulations on overtime hours are scheduled to come into effect as a result of a revision of the law in 2019, and the introduction of a working interval will be promoted. This is intended to lead to a reduction in working hours as a management of work method. Wergeland et al found that reducing working hours from $>7$ hours to 6 hours lowers the incidence of musculoskeletal pain in the neck and shoulders [32]. Furthermore, our previous study suggested that getting enough sleep could reduce the onset of CMSP even when working long hours [18]. Based on this evidence, we presume that managing working hours and sleeping hours can be an effective intervention in workers with musculoskeletal pain.

The deterioration in the ability to function at work among workers with CMSP participating in our study was consistent with previous studies [9, 33]. Since workers who developed CMSP during the study period tended to have decreased ability to function at work, CMSP may be a major factor in exacerbating productivity loss due to presenteeism.

Regarding FABs, comparison of the TSK-J score with the WFun score in workers with musculoskeletal pain indicated that the greater the $\mathrm{FAB}$, the greater the decline in the ability to function at work. A comparison of the change in TSK-J score with the WFun score showed that increased FABs worsened the ability to function at work. However, it has been reported that strongly held FABs are associated with an increased risk of long-term sick leave [34]. Workers with strongly held FABs over-suppress and avoid certain movements due to fear of experiencing pain during movement. When pain-inducing activities are required at work, efficiency and concentration can be reduced, and absences from work due to an inability to work are likely, resulting in a deterioration of ability to function at work and subsequent long-term sick leave. However, from this result, it is unclear if reducing FABs in workers with CMSP can be an effective measure to improve ability to function at work. It is considered that factors other than FABs may affect improvement in the ability to function at work.

Measures to reduce FABs include workplace physi- cal exercise with group-based motivational coaching sessions [35]; approaches to modifying pain perceptions, over-apprehension, and fear of pain-causing behaviors [36]; mindfulness training [37]; and individual pain counseling [38]. In addition, some reports have suggested that the provision of pamphlets containing information on the management of lower back pain are also effective in reducing FABs [39]. Occupational health staff who check work-related activities in detail through workplace patrols can provide workers suffering from musculoskeletal pain with appropriate education and individual consultation concerning suitable workloads. Moreover, occupational health staff may be easier to approach due to a shared workplace. We believe that occupational health staff can contribute to the reduction of FABs, resulting in an improved ability to function at work. While some reports have shown that a decrease in FABs is a predictor of early return to work [40], few approaches to FAB reduction have focused on the ability to function at work, and it is necessary to construct an intervention method involving occupational health staff to address musculoskeletal pain and to verify its effectiveness.

This study had several limitations. First, the research was conducted across three industries; therefore, it is difficult to generalize our findings to all workers because the risk of developing musculoskeletal pain differs depending on the industry. Therefore, more accurate evaluations of actual conditions would only be possible if many differing industries had been involved in this study. Second, because the questionnaire was self-administered, the intent of the questionnaire may not have been well understood, and FABs and the ability to function at work may not have been accurately reflected. Objective measurement of FABs requires observational and psychophysiological evaluations; however, such measurements or knowledge in relation to chronic pain are limited. This limitation applies to all studies assessing FABs. Third, although the questions we used concerning pain sites involved a human body chart, it was difficult to collect detailed information such as whether the pain was localized or generalized. In addition, did not ask any questions concerning psychosocial factors (such as family problems, interpersonal stress at work, job satisfaction, economic problems), and were not able to examine if 
the pain was due to organic disorders. However, $85 \%$ of lower back pain cases are referred to as nonspecific lower back pain for which no cause can be identified despite various tests [41], and psychosocial factors such as stress and anxiety have been reported as risk factors for the development of pain [42], suggesting that psychosocial factors may be involved at various CMSP sites. Therefore, the introduction of more precise measures to prevent CMSP are necessary, including for non-specific musculoskeletal pain. Fourth, FABs are measured only in subjects with musculoskeletal pain and cannot be analyzed if FABs improve and musculoskeletal pain disappears. Therefore, it may not be possible to accurately assess how improvement in FABs will affect the recovery of pain or improvement in the ability to function at work. In the future, more accurate assessments depend on addressing issues related to psychosocial factors and conducting interviews with workers from within specialist areas.

\section{Conclusion}

Two questionnaire surveys were conducted to investigate the risk factors of CMSP and the effect of FABs on the ability to function at work in workers with CMSP. The results suggest that long working hours and increased working hours are risk factors for CMSP. We found that stronger FABs were associated with worse ability to function at work. Improving the FABs of workers with CMSP may have some impact on improving ability to function at work. In the future, we will consider other approaches to improve FABs in the workplace and will perform an intervention study to further our results.

\section{Acknowledgments}

We thank all the employees and the companies who participated in this study. We would like to thank Editage (www.editage.jp) for English language editing.

\section{Conflict of Interest}

The authors have no conflicts of interest to declare.

\section{Funding}

This study was supported by an FY2016 research fund from the Occupational Health Promotion Foundation in Japan.

\section{References}

1. Wada K, Arakida M, Watanabe R, Negishi M, Sato J \& Tsutsumi A (2013): The economic impact of loss of performance due to absenteeism and presenteeism caused by depressive symptoms and comorbid health conditions among Japanese workers. Ind Health 51: 482-489

2. Takura T, Ushida T, Kanchiku T, Ebata N, Fujii K, DiBonaventura M d \& Taguchi T (2015): The societal burden of chronic pain in Japan: A an internet survey. J Orthop Sci 20: 750-760

3. Hattori S, Takeshima N, Kimura N, Yamamoto K, Mizutani A \& Noguchi T (2004): The clinical perspective on chronic pain management in Japan. Pain Clinic 25: 1541-1551 (in Japanese)

4. Matsudaira K, Takeshita K, Kunogi J, Yamazaki T, Hara N, Yamada K \& Takagi Y (2011): Prevalence and characteristics of chronic pain in the general Japanese population. Pain Clinic 32: 1345-1356 (in Japanese)

5. Nakamura $M$, Nishiwaki $Y$, Ushida $T$ \& Toyama $Y$ (2011): Prevalence and characteristics of chronic musculoskeletal pain in Japan. J Orthop Sci 16: 424-432

6. Sugano R, Ikegami K, Michii S, Ando H, Nozawa H, Imoto H, Shima A, Kawatsu Y, Fujino Y \& Ogami A (2019): Musculoskeletal pain in Japanese workers and the relationship between labor productivity by presenteeism and chronic musculoskeletal pain: A cross-sectional study. EOH-P doi: 10.1539/eohp.2019-0003-OA

7. Zinta Podniece; European Agency for Safety and Health at Work (2008): Work-related Musculoskeletal Disorders: Prevention Report. Office for Official Publications of the European Communities, Luxembourg 106pp

8. Patel AS, Farquharson R, Carroll D, Moore A, Phillips CJ, Taylor RS \& Barden J (2012): The impact and burden of chronic pain in the workplace: A qualitative systematic review. Pain Pract 12: 578-589

9. van den Heuvel SG, Ijmker S, Blatter BM \& de Korte EM (2007): Loss of productivity due to neck/shoulder symptoms and hand/arm symptoms: Results from the 
PROMO-study. J Occup Rehabil 17: 370-382

10. Martimo KP, Shiri R, Miranda H, Ketola R, Varonen H \& Viikari-Juntura E (2009): Self-reported productivity loss among workers with upper extremity disorders. Scand J Work Environ Health 35: 301-308

11. Montgomery W, Vietri J, Shi J, Ogawa K, Kariyasu S, Alev L \& Nakamura M (2016): The relationship between pain severity and patient-reported outcomes among patients with chronic low back pain in Japan. J Pain Res 9: 337-344

12. Loeppke R, Taitel M, Richling D, Parry T, Kessler RC, Hymel P \& Konicki D (2007): Health and productivity as a business strategy. J Occup Environ Med 49: 712721

13. de Vries HJ, Reneman MF, Groothoff JW, Geertzen JH \& Brouwer S (2012): Workers who stay at work despite chronic nonspecific musculoskeletal pain: Do they differ from workers with sick leave? J Occup Rehabil 22: 489-502

14. Nakamura M, Toyama $\mathrm{Y}$, Nishiwaki $\mathrm{Y} \&$ Ushida $\mathrm{T}$ (2014): Prevalence and characteristics of chronic musculoskeletal pain in Japan: A second survey of people with or without chronic pain. J Orthop Sci 19: 339-350

15. Generaal E, Vogelzangs N, Penninx BW \& Dekker J (2017): Insomnia, sleep duration, depressive symptoms, and the onset of chronic multisite musculoskeletal pain. Sleep 40. doi: 10.1093/sleep/zsw030

16. Matsudaira K, Palmer KT, Reading I, Hirai M, Yoshimura N \& Coggon D (2011): Prevalence and correlates of regional pain and associated disability in Japanese workers. Occup Environ Med 68: 191-196

17. Kopec JA \& Sayre EC (2004): Work-related psychosocial factors and chronic pain: A prospective cohort study in Canadian workers. J Occup Environ Med 46: 1263-1271

18. Ando H, Ikegami K, Sugano R et al (2019): Relationships between chronic musculoskeletal pain and working hours and sleeping hours: A cross-sectional study. J UOEH 41: 25-33

19. Ganasegeran K, Perianayagam W, Nagaraj P \& Al-Dubai SA (2014): Psycho-behavioural risks of low back pain in railway workers. Occup Med (Lond) 64: 372-375

20. Palmer KT, Reading I, Linaker C, Calnan M \& Coggon D (2008): Population-based cohort study of incident and persistent arm pain: Role of mental health, selfrated health and health beliefs. Pain 136: 30-37
21. Palmer KT, Reading I, Calnan M, Linaker C \& Coggon D (2007): Does knee pain in the community behave like a regional pain syndrome? Prospective cohort study of incidence and persistence. Ann Rheum Dis 66: 11901194

22. Vlaeyen JW \& Linton SJ (2000): Fear-avoidance and its consequences in chronic musculoskeletal pain: A state of the art. Pain 85: 317-332

23. Leeuw M, Goossens ME, Linton SJ, Crombez G, Boersma K \& Vlaeyen JW (2007): The fear-avoidance model of musculoskeletal pain: Current state of scientific evidence. J Behav Med 30: 77-94

24. IASP Task Force on Taxonomy (1994): Classification of Chronic Pain. 2nd ed (Merskey H \& Bogduk N, ed). IASP Press, Seattle 222 pp

25. Fujino Y, Uehara M, Izumi H, Nagata T, Muramatsu K, Kubo T, Oyama I \& Matsuda S (2015): Development and validity of a work functioning impairment scale based on the Rasch model among Japanese workers. J Occup Health 57: 521-531

26. Makishima M, Fujino Y, Kubo T, Izumi H, Uehara M, Oyama I \& Matsuda S (2018): Validity and responsiveness of the work functioning impairment scale (WFun) in workers with pain due to musculoskeletal disorders. J Occup Health 60: 156-162

27. Miller RP, Kori SH \& Todd DD (1991): The Tampa Scale: A measure of kinisophobia. Clin J Pain 7: 51

28. Matsudaira K, Inuzuka K, Kikuchi N, Sakae C, Arisaka M, Isomura T \& Miller RP (2013): Development of a Japanese version of the Tampa Scale for Kinesiophobia (TSK-J): Translation and linguistic validation. Rinsho Seikei Geka 48: 13-19 (in Japanese)

29. Kikuchi N, Matsudaira K, Sawada T \& Oka H (2015): Psychometric properties of the Japanese version of the Tampa Scale for Kinesiophobia (TSK-J) in patients with whiplash neck injury pain and/or low back pain. J Orthop Sci 20: 985-992

30. Bannai A \& Tamakoshi A (2014): The association between long working hours and health: A systematic review of epidemiological evidence. Scand J Work Environ Health 40: 5-18

31. Leiss H, Hucke M, Becede M, Machold-Fabrizii V, Smolen JS \& Machold KP (2019): Effects of a brief workplace-centered consultation for employees with musculoskeletal pain on health outcomes: A prospective cohort study. Sci Rep 9: 5867 
32. Wergeland EL, Veiersted B, Ingre M, Olsson B, Akerstedt T, Bjørnskau T \& Varg N (2003): A shorter workday as a means of reducing the occurrence of musculoskeletal disorders. Scand J Work Environ Health 29: 27-34

33. Agaliotis M, Mackey MG, Jan S \& Fransen M (2014): Burden of reduced work productivity among people with chronic knee pain: A systematic review. Occup Environ Med 71: 651-659

34. Jay K, Thorsen SV, Sundstrup E, Aiguadé R, Casaña J, Calatayud J \& Andersen LL (2018): Fear avoidance beliefs and risk of long-term sickness absence: Prospective cohort study among workers with musculoskeletal pain. Pain Res Treat 2018: 8347120

35. Jakobsen MD, Sundstrup E, Brandt M, Jay K, Aagaard P \& Andersen LL (2015): Effect of workplace- versus home-based physical exercise on muscle response to sudden trunk perturbation among healthcare workers: A cluster randomized controlled trial. Biomed Res Int 2015: 902896

36. Lüning Bergsten C, Lundberg M, Lindberg P \& Elfving B (2012): Change in kinesiophobia and its relation to activity limitation after multidisciplinary rehabilitation in patients with chronic back pain. Disabil Rehabil 34: 852-858

37. Jay K, Brandt M, Jakobsen MD, Sundstrup E, Berthelsen
KG, Schraefel M, Sjøgaard G \& Andersen LL (2016): Ten weeks of physical-cognitive-mindfulness training reduces fear-avoidance beliefs about work-related activity: Randomized controlled trial. Medicine (Baltimore) 95: e3945

38. Takano K, Asada F, Nomura T, Akezaki T, Matsudaira K \& Yamagata H (2016): Physical counseling for low back pain using internet. JJOMT 64: 101-106

39. Slater H, Briggs AM, Watkins K, Chua J \& Smith AJ (2013): Translating evidence for low back pain management into a consumer-focussed resource for use in community pharmacies: A cluster-randomised controlled trial. PLoS One 8: e71918

40. Marchand GH, Myhre K, Leivseth G, Sandvik L, Lau B, Bautz-Holter E \& Røe C (2015): Change in pain, disability and influence of fear-avoidance in a work-focused intervention on neck and back pain: A randomized controlled trial. BMC Musculoskelet Disord 16: 94

41. Deyo RA \& Weinstein JN (2001): Low back pain. N Engl J Med 344: 363-370

42. Krismer M \& van Tulder M; Low Back Pain Group of the Bone and Joint Health Strategies for Europe Project (2007): Strategies for prevention and management of musculoskeletal conditions. Low back pain (nonspecific). Best Pract Res Clin Rheumatol 21: 77-91 


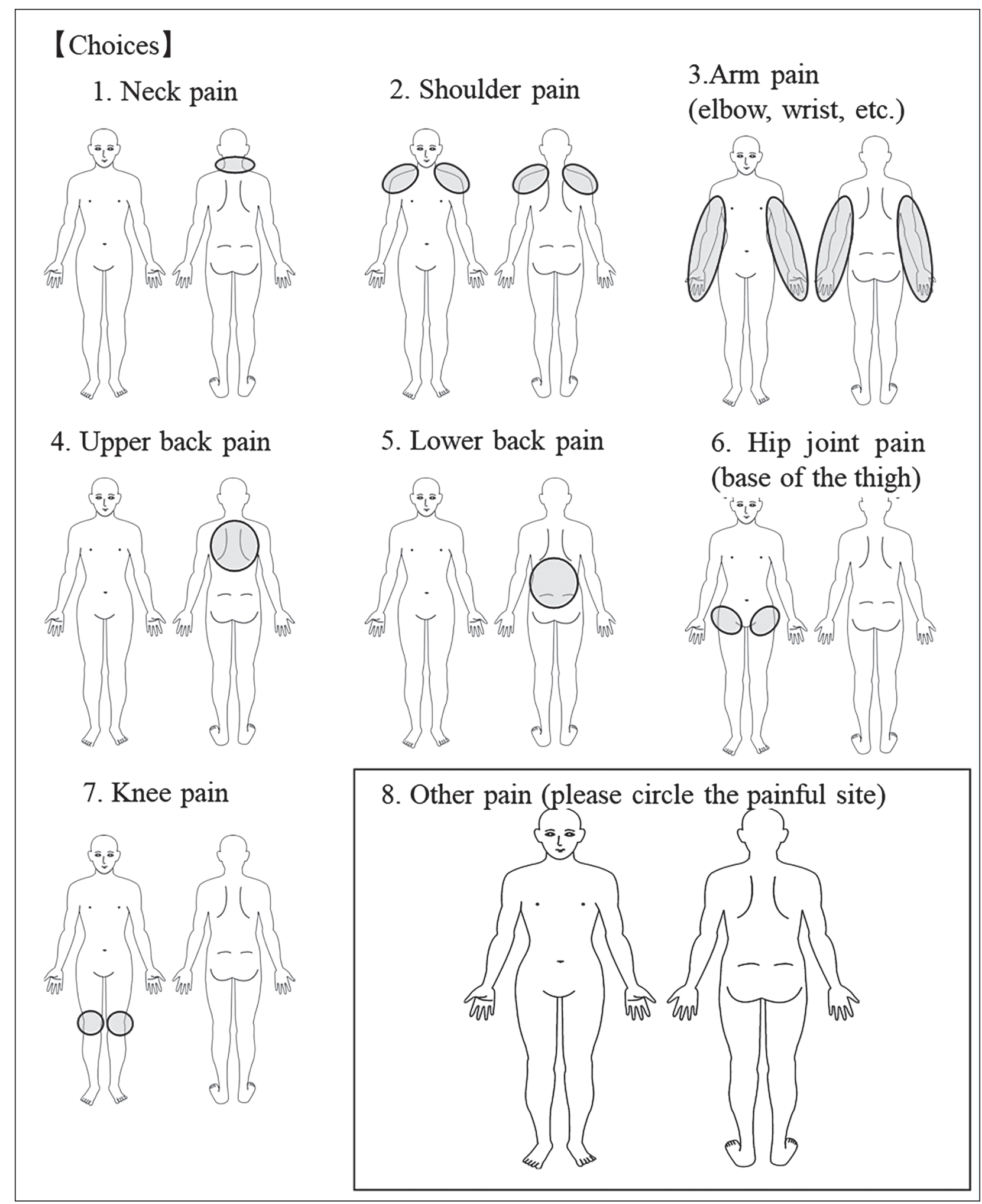

Appendix 1. Diagram included in the questionnaire regarding the site of pain. The site of pain was indicated by the number corresponding to the site of pain or by a circle in the diagram in 8 . 
筋骨格系慢性疼痛を持つ労働者における恐怖回避思考と労働生産性の関連性について; 縦断調査

菅野 良介 ${ }^{1}$, 池上 和範 ${ }^{1}$, 安藤 肇 ${ }^{1}$, 野澤 弘樹 ${ }^{1,2}$, 道井 聡史 ${ }^{1}$, 近藤 三保 ${ }^{2}$, 井本 ひとみ ${ }^{3}$, 志摩 梓 ${ }^{4}$, 河津 雄一郎 ${ }^{4}$, 藤野 善久 ${ }^{5}$, 大神 明 $^{1}$

1産業医科大学 産業生態科学研究所 作業関連疾患予防学研究室

2 スタンレー電気株式会社 秦野製作所 業務部

3 九州労働金庫 統括本部 人事部

${ }^{4}$ 株式会社平和堂 教育人事部 健康サポートセンター

5 産業医科大学 産業生態科学研究所 環境疫学研究室

要旨: 本研究の目的は, 筋骨格系慢性疼痛の危険因子を特定し, 慢性筋骨格系疼痛を持つ労働者の恐怖回避 思考が生産性に与える影響を調査することである。2016年4月から 2017年3月にかけて3つの異なる業種の従業 員に対して自記式質問紙を用いて縦断調査を実施し, 質問紙には基本属性, 業務関連因子, 筋骨格系慢性疼痛, Work Functioning Impairment Scale(WFun), 日本語版Tampa Scale for Kinesiophobia(TSK-J)に関して回答を求めた。 ロジ スティック回帰分析を実行して筋骨格系慢性疼痛に影響を与える要因を分析したところ, 年齢 $($ オバ比 $[\mathrm{OR}]=$ $1.02,95 \%$ 信頼区間 $[\mathrm{CI}]: 1.00-1.03)$, 平均労働時間 $(\mathrm{OR}=1.18,95 \% \mathrm{CI}: 1.04-1.33)$, および労働時間の変化 $(\mathrm{OR}=1.18$, 95\%CI：1.02-1.37)に扔いて慢性筋骨格系疼痛の発生と関連が見られた。 また, 多元配置分散分析を行って, 恐怖回 避思考と筋骨格系慢性疼痛, および恐怖回避思考と労働機能障害の関係を分析したところ, 恐怖回避思考が強いほど WFunの得点が大きくなり, 恐怖回避思考が強まるとWFunの得点も増加することが示された，本研究より，長時間 労働または労働時間の増加が慢性筋骨格系疼痛の危険因子であり, 慢性筋骨格系疼痛を持つ労働者の恐怖回避思考 の増強と労働機能障害の悪化が関連していることが示された。また, 恐怖回避思考を改善するアプローチは筋骨格 系慢性疼痛を抱える労働者にとって有効である可能性がある.

キーワード : 恐怖回避思考, 筋骨格系慢性疼痛, 労働生産性, プレゼンティーズム, 産業保健. 